Neuropathology. Baltimore, Williams \& Wilkins, 1963). Yakovlev and Wadsworth (1946) described schizencephalic porencephalies of developmental origin and encephaloclastic porencephalies caused by destruction of cerebral tissue. A wide variety of etiological factors and clinical findings are reported (Mednick JP, Jerva MJ, Millichap JG. Trans Am Neur Assoc 1966;301-303). Hemorrhagic infarction following a germinal matrix hemorrhage in a preterm infant is a frequent destructive cause. Other causes include trauma, vasculopathy secondary to maternal cocaine abuse or congenital infections such as cytomegalic inclusion disease, bleeding disorders, including factor V Leiden and collagen IV A1 mutation with microangiopathy, as in familial autosomal dominant porencephaly, described in the above report.

\title{
VASCULAR ABNORMALITIES IN ALTERNATING HEMIPLEGIA
}

Skin and/or muscle biopsies in 4 patients, ages 18 months, 8, 9, and 16 years, with alternating hemiplegia of childhood (AHC) were examined by electron microscopy and compared with healthy controls in a study at University Hospital, Lille, France. Vascular abnormalities present in both skin and muscle small vessels included endothelial vacuoles, intracytoplasmic vacuoles in vascular smooth muscle cells (VSMCs) in the tunica media, apoptotic nuclei, and isolation of VSMCs from neighboring cells. A primary or secondary vascular pathophysiology is suggested for AHC. (Auvin S, Joriot-Chekaf S, Cuvellier JC, et al. Small vessel abnormalities in alternating hemiplegia of childhood. Neurology February (2 of 2) 2006;66:499-504). (Reprints: Dr S Auvin, Service de Neurologie pediatrique, Hopital Roger Salengro, Boulevard du Pr J Leclercq, 59037 Lille Cedex, France).

COMMENT. AHC is characterized by 3 phases; 1) abnormal eye movements and dystonic episodes; 2) episodic hemiplegia and developmental delay; and 3) persistent neurologic deficits. Onset is before 18 months of age, and symptoms resolve during sleep. Formerly ascribed to a migraine equivalent, an epilepsy, or movement disorder, the present evidence suggests a neurovascular mechanism, similar to the cerebral autosomal dominant arteriopathy with subcortical infarcts and leukoencephalopathy (CADASIL).

\section{INTRACRANIAL NEOPLASMS}

\section{SUPRASELLAR GERMINOMA AND GROWTH RETARDATION}

Three patients, ages 9, 12, and 13 years ( 1 boy and 2 girls), diagnosed with intracranial germinoma are reported from University Children's Hospital Homburg, Germany. Presenting symptoms and signs prompting an MRI were nausea, vomiting, strabismus, and intermittent headache for 1 year in case 1, migraine in case 2, and a 3-year history of growth retardation in case 3. Patients 1 and 2 also had a history of growth retardation for 2 years. MRI showed tumors in the pituitary region in cases 1 and 2 , and a thickened pituitary stalk in case 3. Clinical and laboratory findings showed panhypopituitarism, subclinical diabetes insipidus and hypothyroidism, and growth hormone deficiency in cases 1,2, and 3, respectively. CSF levels of Beta-human chorionic gonadotrophins (B-hCG) were not elevated, and diagnosis of germinoma was confirmed by 